\title{
Editorial: Mental Health as a Public Health Issue
}

\author{
Theodore H. Tulchinsky, MD, MPH, ${ }^{1}$ \\ Antoine Flahault, $\mathrm{MD}, \mathrm{PhD},{ }^{2}$ \\ Itzhak Levav, MD, MSc, ${ }^{3}$ \\ Ezra Susser, MD, DrPH, ${ }^{4}$ \\ Viviane Kovess-Masfety, MD, PhD, ${ }^{5}$ \\ Soumitra Pathare, MD, ${ }^{6}$ \\ Irena Gryga, $\mathrm{MD}, \mathrm{PhD}^{7}$
}

Recommended Citation: Tulchinsky TH, Flahault A, Levav I, Susser E, KovessMasfety V, Pathare S, Gryga I. Editorial: mental health as a public health issue. Public Health Reviews. 2012;34: epub ahead of print.

"There is no health without mental health"

\section{INTRODUCTION}

The brain-mind-body-society connections in preventing avoidable disease and delaying death are fundamental in public health. They are interconnected: adverse environmental conditions reflected in deprivation and trauma leave their marks on physical and mental health. Poor mental health and physical illness are interactive, and this needs to be clearly addressed in the education of the public, providers and policy makers in the health and related sectors.

\footnotetext{
${ }^{1}$ Deputy Editor, Public Health Reviews; Emeritus Professor, Braun School of Public Health, Hebrew University-Hadassah, Ein Karem, Jerusalem, Israel.

${ }^{2}$ Editor in Chief, Public Health Reviews; Professor of Public Health at University Paris Descartes, School of Medicine, Sorbonne, Paris Cité, France.

${ }^{3}$ Department of Community Mental Health, Faculty of Health Sciences and Social Welfare, University of Haifa, Haifa, Israel.

${ }^{4}$ Mailman School of Public Health, Columbia University, New York; and New York State Psychiatric Institute, New York, NY, USA.

${ }^{5}$ Ecole des Hautes Études en Santé Publique (EHESP), Paris and Rennes, France.

${ }^{6}$ Centre for Mental Health Law and Policy, India Law Society, Pune, India.

${ }^{7}$ School of Public Health, National University of Kyiv-Mohyla Academy, Kiev, Ukraine.
} 
In this issue of Public Health Reviews, we address some of the subjects in this complex mesh of relationships ranging from the gene structure to the rights of persons with disabilities.

Mental health, defined by the World Health Organization as "a state of well-being in which the individual copes with the usual stresses of family and community living" or as "fulfillment of each person's potential" is at the heart of public health. In practice, this means that health promotion and all other levels of prevention, research, professional education and policies should transcend the outdated separation of mental health as a closed and isolated domain. Public mental health as a component of public health, is a continuous developing field, yet there is still an absence of a range of well coordinated preventive, promotive, curative and rehabilitation services. This situation is current in many high-income countries and even more so in developing countries.

The societal component of poverty and its associated deprivations, such as poor nutrition are key in community mental health, for example, to prevent damaging conditions that can occur in early life and lead to longterm consequences. Health promoters, policy makers and providers need to understand these interactions. It is not a mere doctor-patient issue, but a total of social and political issues, as has been argued by pioneers such as Rudolph Virchow over a century and a half ago, and indeed many before and following him. All of them have linked the cellular biomedical model with social medicine. ${ }^{2}$

To repeat ourselves, mental health-still a neglected field in many countries of the world - is as fundamental to public health as is physical health. There are many reasons for the link: mental disorders are frequent, often cited as affecting one in four persons so that no society is immune to them; they are costly for individuals and society; and the comorbidity of physical and mental disorders affects the individual, the family, the health system and society. Health promotion in these interactive domains overlaps, and the benefits of primary prevention action are common to all. This interconnectedness is the reason that this issue of PHR is fully devoted to mental health, and attempts to deal with key aspects that constitute a small sample of a large universe of themes.

\section{SCIENCE AND MENTAL HEALTH}

As $P H R$ tradition dictates, the current issue opens with a commentary based on an interview with renowned scientist, Professor Ada Yonath, 2009, Nobel Prize winner in Chemistry. Her career in basic sciences is highlighted 
by the influence of her personal life story. Her work on the development of cellular internal structure is vital to biological aspects of physical illness, such as the interaction of antibiotics with bacterial ribosomes. ${ }^{3}$ Other work by Eric Kandel (Nobel Prize in Medicine, 2000) ${ }^{4}$ and many others more recently have demonstrated the interaction of genetic and the biology of cellular structure and function, which are increasingly identified with mental dysfunction. This provides an important realm of science in the search for more effective means of approaching mental disorders.

Two guest editorials are reprinted with kind permission from the American Journal of Public Health: Perry and colleagues address the centrality of mental health in a public health agenda, ${ }^{5}$ and Power presents a public health approach to mental health promotion and mental illness prevention, and a strategy to promote individual, family, and community resilience. $^{6}$

\section{EPIDEMIOLOGY AND MENTAL HEALTH}

Our original articles include Weinberg and colleagues' review of the epidemiology of mental disorders based on the World Mental Health Survey Consortium, a WHO and Harvard University collaboration of 28 countries that used uniform methods and procedures and followed the same rules of analysis. ${ }^{7}$ The information that was generated is an invaluable resource for decision makers and all the stakeholders of both the public health and mental health domains. Morris and colleagues further expand the description of the current mental health situation world-wide, through an overview of a survey of mental health resources in 184 countries showing "the urgent need to scale up resources within countries to meet the high and growing burden of mental disorders". ${ }^{8}$

Hermann and Jané-Llopis define health promotion in mental health as "actions that support people to adopt healthy ways of life and create living conditions and environments conducive to health". They review evidence of cost-effective interventions, such as in parenting, schools, workplaces, older age, and other social support domains with partnerships and linkages between mental health and human rights. Mental health promotion is vital in low-income countries and in disaster situations and other emergencies. Innovation, adaptation and evaluation, mobilized by effective advocacy, are needed to integrate mental health promotion in the public health agenda. ${ }^{9}$ 


\section{THE RIGHTS OF PEOPLE WITH DISABILITIES}

Pathare and Shields discuss the implications of the International Convention on the Rights of Persons with Disabilities (CRPD), with specific regard to persons with mental disabilities in achieving equal recognition before the law and the right to exercise their legal capacity. This should be recognized as an inalienable right of people in all societies. Exercising legal capacity includes making decisions about employment, medical or psychosocial treatment, property, finances, family, and participation in community activities. ${ }^{10}$ Shirli Werner using the CRPD addresses the importance of developing decision-making skills among people with intellectual disability and their opportunities for decision-making, with professional support, fostering the philosophy of person-centered planning. ${ }^{11}$ Stuart and ArboledaFlórez discuss the frequency and impact of stigma on people with mental disorders and their place in society, and recommend that public health agencies view stigma reduction as part of their continuous responsibility. ${ }^{12}$

\section{COMPLEXITY AND COSTS}

Rice and colleagues review Autism Spectrum Disorders (ASD) showing the complexity of determining the relevant causative factors in the identification of increasing numbers of children with an ASD, and the impact this has on individuals, families, and communities. ${ }^{13}$ Perla Werner addresses family impacts of persons with mild cognitive impairment noting that studies are needed for the development of interventions necessary to reduce cost and social burden of care giving. ${ }^{14}$ Gvion and Apter review issues related to suicide, which WHO estimates in 2020 will cost the lives of some 1.5 million people, with ten to twenty times more attempted suicides worldwide. They examine factors in causation and prevention of suicide. ${ }^{15}$ Storr and colleagues present the co-occurrence of mental and behavioral disturbances with drug abuse addressing the etiology, course, and treatment of psychiatric problems among adolescents of this global pandemic. ${ }^{16}$

\section{INTERACTION OF MENTAL HEALTH AND PHYSICAL DISEASES}

Coughlin reviews the relationship between viral illnesses and mental health, especially between anxiety and depression with viral diseases such as influenza A (H1N1) and other influenza viruses, varicella-zoster virus, herpes simplex virus, human immunodeficiency virus/acquired immune deficiency syndrome, and hepatitis $\mathrm{C} .{ }^{17}$ The topic of mental health must be recognized 
as part of health care and public health, and its chronicity is no different than many diseases that require lifelong management such as hypertension and diabetes. In the case of noncommunicable diseases skilled multidisciplinary action has brought great rewards in prevention and health promotion reducing morbidity and mortality. The interaction between infection and chronic diseases, including cancer and others, may well show parallel issues in the relationship of infection with the burden of mental health. Additionally, the inverse relationship must be recognized when mental health issues influence physical health, as Fleishman and Lurie review the evidence of high risk of cardiovascular mortality among persons with schizophrenia. ${ }^{18}$

\section{MENTAL HEALTH IN DIFFERENT SETTINGS}

Regional specific challenges and solutions are addressed by several authors, including Burns, who reviews the burden of disease, risk factors and natural history of schizophrenia in Africa with specific socio-economic, political and cultural transformations in that context ${ }^{19}$; Minoletti and colleagues, discuss community mental health services in Latin America ${ }^{20}$; and Petrea presents the dilemma of post Soviet mental health in many countries of the former Soviet Union. ${ }^{21}$

\section{COMMUNITY MENTAL HEALTH CARE}

Psychotropic medications and community service delivery models have changed the face of psychiatric care with management of many mental illnesses in the community rather than in institutional settings. Innovative methods and policies are needed, uniting psychological and physical health into a coordinated public health system. Psychological health should address, delineate, and target at-risk groups along the three levels of prevention-primary, secondary and tertiary.

Health promotion for community mental health, with a focus on overall psychosocial wellness can be distinguished from diagnosed mental illness. Improved coordination and integration of community mental health and physical health activities requires a focus on integration of core education components for public health workers.

Concern that mentally ill persons are contributing to the increase in the homeless population in the United Kingdom and the United States is promoting reappraisal of mental health policies. Many of these individuals end up, inappropriately, in the criminal legal system due to aberrant behaviors. 


\section{GLOBAL RESPONSES TO THE CHALLENGES OF MENTAL HEALTH}

Studies require collaboration among social scientists, epidemiologists, biostatisticians, anthropologists, geneticists, and other disciplines in order to increase knowledge of factors contributing to mental illness and to promote the search for causes and treatments. WHO regards mental disorders as one of the major challenges of global public health. The recent WHO resolution on the need for a comprehensive, coordinated response to address mental disorders from health and social sectors at the country level ${ }^{22}$ was reinforced by the WHO's Comprehensive Mental Health Action Plan 2013-2020 adopted by the World Health Assembly. ${ }^{23}$ Progress in development of new approaches to health is an important element of the New Public Health.

We cannot continue to maintain the separation between biological, psychological and social aspects of health. The challenge for public health is to play a leading role in societal efforts to deal with mental disorders and mental health as an integral part of its mandate. The problems are so widespread and affect all of us directly or indirectly. New science may help us find better prevention and management but the issue deserves our full attention now as an integral part of the New Public Health. ${ }^{24}$

\section{EPILOGUE}

Mental health is a complex public health challenge, in which the environmental context plays an important role.

Research and development dedicated to mental disorders during past decades has dramatically transformed medical and psychiatric practice, adding quality of life for millions of patients. Thanks to new antidepressants and antipsychotics with much less frequent adverse reactions, people can return to work much more quickly, Parkinson-like syndromes are less frequent and patients are less stigmatized, and persons affected by psychotic disorders are able to be treated without hospitalization, or with shorter hospital stays. Improving the quality of psychotherapeutic and psychosocial care, and of primary care, enhancing the capacity of community-based care, using interventions purported to improve the quality of life, would facilitate coping with the costs and social burden of mental illnesses.

There is however a huge issue of access to mental health care and facilities, particularly in the developing world ${ }^{8}$ and as mentioned in the former Soviet bloc. ${ }^{21}$ More attention needs to be focused on risk-based and targeted prevention and preventive care early in life, from prenatal care to 
well child care and on into preschool and school age. The true magnitude of the epidemiology of mental disorders is still unclear because so much mental illness is undetected and untreated. In addition, often people lack health insurance coverage for these and other related conditions.

New breakthroughs in the neurobiology, therapeutics and epidemiology of mental illness are likely to emerge in the coming decade, but prevention and early treatment will still be needed using "best practice" tools. Legal and decision-making rights of persons with disabilities are issues that involve the general public as well as the caring professions. ${ }^{10,11}$ The movement away from segregation and exclusion from society is an ongoing process and will take a long time to develop pressing and adequate community- based programs. This is seen in the post Soviet approaches to mental health care ${ }^{21}$ but also in western societies where custodial facilities were closed without meaningful attention to developing sufficient community and societal support systems.

Most importantly, the World Mental Health Survey Consortium studies have found that the treatment gap (the difference between the true and the treated prevalence) was uniformly high in the large number of participating countries, including those with better developed mental health services. ${ }^{7}$ The Consortium findings that no country or continent could claim immunity with regard to mental and behavioral disorders are supported by analogous studies that were conducted by WHO. ${ }^{8}$

Based on the evidence accrued thus far, mental health services would need to do much soul-searching and note that for some disorders more persons are not treated than treated. With regard to the young, the treatment gap is even higher than among adults. Solutions are possible, but mental health would need to occupy the central role it deserves, among other strategies: by raising the profile of health promotion, ${ }^{5,6,9}$ by extending the concern to medical comorbid problems ${ }^{17,18}$ and by the development of new strategic alliances. ${ }^{20}$ WHO strongly recommends inclusion of psychiatric care into the primary health care system to make it largely accessible in developing countries, claiming that mental health care does not always need to be provided by specialists, that for most patients primary care could provide adequate treatment with proper guidance and referral.

As noted in the introduction, topics that are included in this issue of $P H R$ were selected to illustrate the rich and expanding mental health field in public health. Recognition of the importance of social inequality, deprivation and trauma make clear the advocacy role of public health for reductions of health disparities and preventing diseases and traumas that lend themselves to mental distress on a long term basis. 
The drama of mental health and its relation to physical health within public health has been described here as Act 1 of this saga. We shall see Acts 2 and 3 in the years to come.

\section{REFERENCES}

1. World Health Organization. Promoting mental health: concepts, emerging evidence, practice, summary report. Geneva: WHO; $2004 . \quad$ Available from URL: http://www.who.int/mental_health/evidence/en/promoting_mhh. pdf (Accessed 14 September 2013).

2. DeWalt DA, Pincus T. The legacies of Rudolf Virchow: cellular medicine in the 20th Century and social medicine in the 21st Century. Isr Med Assoc J. 2003; 5:395-7.

3. Leighton, L. Science and public health: Professor Ada Yonath, Weizmann Institute of Science, Rehovot, Israel, Nobel Laureate in Chemistry, 2009. Public Health Rev. 2013;34: epub ahead of print.

4. Kandel ER. Nobel lecture: The molecular biology of memory storage: a dialog between genes and synapses". Nobelprize.org. Nobel Media AB; 2013. Available from URL: http://www.nobelprize.org/nobel_prizes/medicine/ laureates/2000/kandel-lecture.html (Accessed 12 September 2013).

5. Perry GS, Presley-Cantrell LR, Dhingra S. Addressing mental health promotion in chronic disease prevention and health promotion. Am J Public Health. 2010;100:2337-9.

6. Power AK, Transforming the nation's health: next steps in mental health promotion. Am J Public Health. 2010;100:2343-6.

7. Weinberg L, Whiteford H, Caldas de Almeida J, Aguilar-Gaxiola S, Levinson D, et al. Translation of the World Mental Health Survey data to policies: an exploratory study of stakeholders' perceptions of how epidemiologic data can be utilized for policy in the field of mental health. Public Health Rev. 2012;34: epub ahead of print.

8. Morris J, Lora A, McBain R, Saxena S. Global Mental Health Resources and Services: a WHO Survey of 184 countries. Public Health Rev. 2012;34: epub ahead of print

9. Herrman H, Jané-Llopis E. The status of mental health promotion. Public Health Rev. 2012;34: epub ahead of print.

10. Pathare S, Shields LS. Supported decision-making for persons with mental illness: a review. Public Health Rev. 2012;34: epub ahead of print.

11. Werner S. Individuals with intellectual disabilities: a review of the literature on decision-making since the Convention on the Rights of People with Disabilities (CRPD). Public Health Rev. 2012;34: epub ahead of print.

12. Stuart H, Arboleda-Flórez J. A public health perspective on the stigmatization of mental illnesses. Public Health Rev. 2012;34: Epub ahead of print. 
13. Rice CE, Rosanoff M, Dawson G, Durkin MS, Croen LA, Singer A, YearginAllsopp M. Evaluating changes in the prevalence of the autism spectrum disorders (ASDs). Public Health Rev. 2012;34: epub ahead of print.

14. Werner P. Mild cognitive impairment and caregiver burden: a critical review and research agenda. Public Health Rev. 2012;34: epub ahead of print.

15. Gvion Y, Apter A. Suicide and suicidal behavior. Public Health Rev. 2012;34: epub ahead of print.

16. Storr CL, Pacek LR, Martins SS. Substance use disorders and adolescent psychopathology. Public Health Rev. 2012;34: epub ahead of print.

17. Coughlin SS. Anxiety and depression: linkages with viral diseases. Public Health Rev. 2012;34: epub ahead of print.

18. Fleishman A, Lurie. I. Cardiovascular mortality and related risk factors among persons with schizophrenia: a review of the published literature. Public Health Rev. 2012;34: epub ahead of print.

19. Burns JK, The social determinants of schizophrenia: an African journey in social epidemiology. Public Health Rev. 2012;34: epub ahead of print.

20. Minoletti A, Galea S, Susser E. Community mental health services in Latin America for people with severe mental disorders. Public Health Rev. 2012;34: epub ahead of print.

21. Petrea I. Mental health in former Soviet countries: from past legacies to modern practices. Public Health Rev. 2012;34: epub ahead of print.

22. Sixty-sixth World Health Assembly. Comprehensive mental health action plan, 2013-2020. WHA66.8, Agenda item 13.3. 27 May 2013. Available from URL: http://apps.who.int/gb/ebwha/pdf_files/WHA66/A66_R8-en.pdf (Accessed 12 September 2013).

23. Comprehensive Mental Health Action Plan 2013-2020. Developed based on the above resolution and adopted by the World Health Assembly resolution WHA 66.8 on 27th May 2013.

24. Tulchinsky TH, Varavikova EA. The New Public Health, Third Edition. 2013. Chapter 7. 